\title{
Crowdsourcing Tools for Disaster Management: A Review of Platforms and Methods
}

\author{
Marta Poblet ${ }^{1,2}$, Esteban García-Cuesta, ${ }^{3}$ Pompeu Casanovas ${ }^{1}$ \\ RMIT University, Melbourne VIC 3001 Australia \\ ${ }^{1} \mathrm{UAB}$ Institute of Law and Technology, Campus UAB, 08193 Bellaterra, Spain \\ ${ }^{3}$ iSOCO, Madrid, Spain
}

marta.pobletbalcell@rmit.edu.au, egarcia@isoco.com,pompeu.casanovas@uab.cat

\begin{abstract}
: recent advances on information technologies and communications, coupled with the advent of the social media applications have fuelled a new landscape of emergency and disaster response systems by enabling affected citizens to generate georeferenced real time information on critical events. The identification and analysis of such events is not straightforward and the application of crowdsourcing methods or automatic tools is needed for that purpose. Whereas crowdsourcing makes emphasis on the resources of people to produce, aggregate, or filter original data, automatic tools make use of information retrieval techniques to analyze publicly available information. This paper reviews a set of online tools and platforms implemented in recent years which are currently being applied in the area of emergency management and proposes a taxonomy for its categorization.
\end{abstract}

Keywords: emergency management, disaster management, crowdsourcing, crowdsensing, micro-tasking, platforms, mobile apps.

\section{Introduction}

Mobile technologies and social media have transformed the landscape of emergency management and disaster response by enabling disaster affected citizens to produce real time, local information on critical events. Hurricane Sandy offers one of the most recent examples of large volumes of user-generated data: "social media use during Hurricane Sandy produced a 'haystack' of half-a-million Instagram photos and 20 million tweets" [1]. The growing interest on how to leverage social media for disaster management comes as no surprise, nor the number of platforms and tools that aim at making sense of this vast amount of crowdsourced data for emergency management and response. These initiatives come from multiple domains: governments, companies, not-for-profit organizations, volunteer and technical communities, etc. In 2012, the American Red Cross launched the Digital Operations Center, a social mediamonitoring platform dedicated to humanitarian relief [2]. In Australia, the Government Crisis Coordination Centre (CCC), an all-hazards management facility supporting protective security, counter terrorism, pandemics, and other natural hazards, has recently started to monitor social media as a new source of data from which crisis 
coordinators can obtain awareness of developing situations [3]. A number of digital volunteer organizations (i.e. the Standby Task Force, Humanity Road, and Open Crisis) have integrated social media monitoring in their workflows when cooperating with large humanitarian organizations in disaster relief operations.

Two different technology approaches to disaster management can be identified from the literature review: (i) data oriented; (ii) communication oriented. Data oriented approaches rely on intensive aggregation, mining, and processing of unstructured data sourced from different social media (e.g. Twitter, Facebook, Instagram, etc.) to generate early alerts. An example of such approach is the Australian Emergency Situation Awareness (ESA) system [4,3]. ESA is a platform for emergency situation awareness which captures and analyzes messages from different sources, not to replace existing procedures and information sources but to provide additional data with many potential applications: pre-incident activity, near real time notification of incidents, or community response to emergency warning [3]. This approach has proved to be faster than other traditional meteorological warning systems [5]. In that study the authors claimed that the system provides two minutes delayed alert improving the six minutes delay of the Japan Meteorological Agency (JMA) and with a 93\% of accuracy. Other similar studies have been also performed showing similar capabilities [6,7].

The second approach aims at enhancing communication between people and disaster management systems by allowing seamless interaction between them. One example of this type of collaboration is the NetQuakes ${ }^{1}$ project promoted by the U.S. Geological Survey, which aims to get a denser and more uniform spacing of measurements by using a cheaper Wi-Fi capable seismograph and asking volunteers to send information through their private networks.

Somewhat halfway between these two approaches, there is a set of hybrid platforms and tools leveraging people's workforce in the different tasks of a disaster management lifecycle. This paper aims at offering a general overview of technological solutions that are currently applied in the area of emergency management and have in common the use of data generated and/or processed by large numbers of citizens via social media and social networks. By focusing and classifying different solutions based on their origin, methods, functionalities, and prospective end users we can outline a number of different models to address crowdsourced emergency management. In section 2 we introduce new trends combining local information with global response. Section 3 offers an overview of crowdsourcing definitions and roles and Section 4 puts those roles into the context of the disaster management cycle. Section 5 analyzes the features and functionalities of platforms and mobile applications and proposes a classification. The paper concludes by stressing the need for further research on crowdsourcing roles models matching the needs of each phase of the disaster management cycle.

\footnotetext{
${ }^{1}$ http://earthquake.usgs.gov/monitoring/netquakes/
} 


\section{Local information and global response}

The velocity, variety, and volume of social media information-as a particular type of big data — can be leveraged in all phases of an emergency management lifecycle. Increasingly, emergency organizations are embracing social media and mobile apps to issue alerts and provide updates for incidents (i.e. the official Facebook and Twitter accounts from fire services, rescue and civil protection organizations, etc.).With 241 million monthly active users, more than 35 languages supported, and over 500 million tweets sent per day, Twitter is perhaps the most popular outlet when it comes to disseminate disaster-related information. A growing literature on methods to mine Twitter data for disaster management confirms this emerging trend $[8,9,10,11]$.

In contrast, this trend is not always matched by the monitoring of social media by emergency organizations, and it is frequent to read in the official profiles that accounts are "not monitored 24/7", so that the usual 000 or 999 telephone numbers should be dialed instead. Operational barriers to adopt a proactive role have been explored by recent research [12,13]. Apart from the fact that, in emergency situations, heavy usage of communication networks may cause traffic disruptions and compromise the delivery of updated information, the underlying assumption is that reliable information only travels in one direction: from authorities to citizenry [14].

The platforms reviewed in this paper challenge this notion in two different senses: (i) typically, they consider affected populations as first responders in an emergency situation, so that critical information can actually flow in two directions and facilitate peer-to-peer disaster management networks; (ii) they also empower online volunteers and organizations to offer a global response by allowing their participation in a number of tasks: social media monitoring, data filtering, tagging, geolocation of events, etc. By including the citizens ("the crowd") into the platforms, either by providing information about the disaster or as volunteers for performing specific tasks, they are able to extract global knowledge and trigger a global response based on the local information.

\section{Crowdsourcing: the power of crowd}

The term crowdsourcing was first coined by Jeff Howe in 2006 when referring to "the act of taking a job traditionally performed by a designated agent (usually an employee) and outsourcing it to an undefined, generally large group of people in the form of an open call" [15]. To Howe, crowdsourcing finds its contemporary roots in the open source software movement:

Open source revealed a fundamental truth about humans that had go largely unnoticed until the connectivity of the Internet brought it into high relief: labor can often be organized more efficiently in the context of community than it can in the context of a corporation. The best person to do a job is the one who most wants to do that job; and the best people to evaluate their performance are their friends and peers who, by the way, will enthusiastically pitch in to improve the final product, simply for the 
sheer pleasure of helping one another and creating something beautiful from which they all will benefit [16].

Since Howe's first definition, different crowdsourcing categories, dimensions, and typologies have recently been discussed in the literature [17, 18, 19, 20, 21, 22, 23, 24]. Other studies consider crowdsourcing as part of the broader paradigm of collective intelligence [25] and review the similarities, overlapping and gaps between human computation, crowdsourcing, social computing and data mining [26].

The three key elements intersecting in Web-based crowdsourcing are the crowd, the outsourcing model, and advanced Internet technologies [23]. According to their definition, "crowdsourcing is a sourcing model in which organizations use predominantly advanced Internet technologies to harness the efforts of a virtual crowd to perform specific organizational tasks" [23]. Another recent definition by Chamales also highlights the technological component of crowdsourcing [27]:

Crowdsourcing technology brings together a distributed workforce of individuals in order to collect resources, process information, or create new content. The implementation of a crowdsourcing system can vary widely, from complex online websites that coordinate a million simultaneous workers to low-tech, ad hoc approaches that use a shared spreadsheet." [27].

At present, indeed, technology has expanded the range of available crowdsourcing methods to the point that the concept has become an umbrella term that covers multiple ways to collect and share information, respond to labor offers or contests, volunteer for a number of tasks, etc. The size and composition of the crowd can also help to determinate whether the crowdsourced effort is unbounded (anyone can participate) or bounded to "a small number of trusted individuals" [28]. In this line, Prpic et al. [29] have distinguished different types of "crowd capital" generation based on the "crowd capabilities" of organizations as they engage with the dispersed knowledge of individuals (i.e. public crowd, public crowd curated, and captive crowd).

We can further distinguish the role of the crowd based on the type of data being processed and the level of participation involved. This leads to four types of crowdsourcing roles based on: (i) type of data processed (raw, semi-structured, and structured data), (ii) participants' level of involvement (passive or active) and, (iii) skills required to fulfill the assigned task (basic or specialized skills). Figure 1 below shows these four roles based on how the crowd is involved in the process of generating and adding value to the knowledge chain process. 


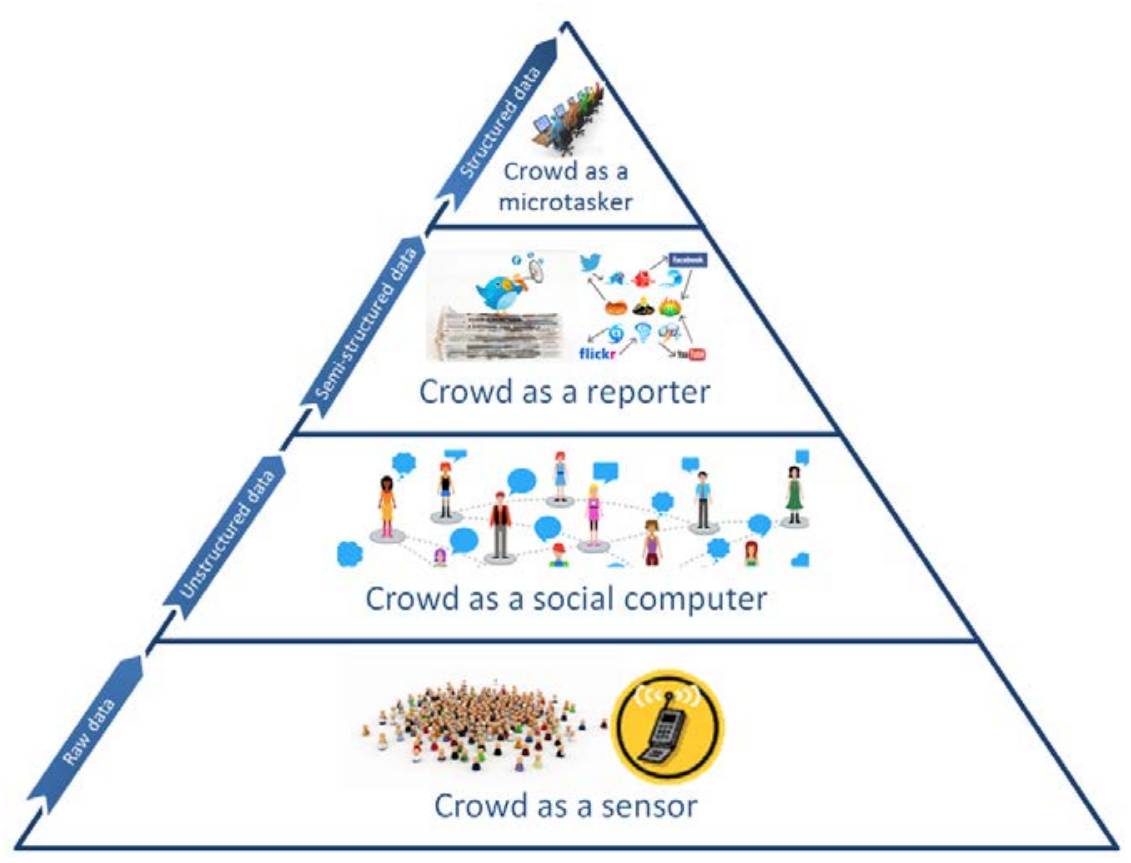

Fig. 1. Crowdsourcing roles based on users' involvement and level of data processing

The lower tiers of the pyramid represent users who generate raw or unstructured data by the mere use of mobile phones, tablets, etc. (crowd as a sensor) or their either occasional or regular use of social media (crowd as a social computer). In contrast, the two top tiers include users with an explicit, conscious use of a priori knowledge to achieve a specific goal (crowd as a reporter and crowd as a microtasker). Moving from lower to higher levels in the pyramid also implies a shift in the quality of the obtained data. From a knowledge generation and data processing point of view we are ranging from raw data, unstructured data, or semi-structured data, to structured data (which also become interpreted data resulting from the execution of the process). Whereof, lower roles in the pyramid produce raw data and higher roles high valued data which are related with the action of solving a specific problem (e.g. labeling an image). Such a categorization also implies different levels of effort by the crowds involved:

i) Crowd as sensors: people generate raw data just because some processes are automatically performed by sensor-enabled mobile devices (e.g. processes run in the backend by GIS receivers, accelerometers, gyroscopes, magnetometers, etc.) which can be later on used for a purpose (i.e. mobile phone coordinates for positional triangulation, traffic flow estimates, etc.). This type of data collection has been defined elsewhere as "opportunistic crowdsourcing" [30]. Opportunistic crowdsourcing requires very low data 
processing capabilities (if any) on the side of participants and is the most passive role in the contributing information chain.

ii) Crowd as social computers: people generate unstructured data mostly by using social media platforms for their own communication purposes (e.g. sharing contents or socializing in Facebook, Twitter, Instagram, etc.). Social media users do not process information in any specific form, but these data can later be reused to extract semantically structured information. As in the previous role, there is no explicit participatory effort in any crowdsourced initiative or project).

iii) Crowd as reporters: people offer first-hand, real-time information on events as they are unfolding (e.g. they tweet about a hurricane making landfall and the reporting damages in a specific location). This usergenerated content already contains valuable metadata added by users themselves (e.g. hashtags) than can be used as semi-structured, preprocessed data.

iv) Crowd as microtaskers: people generate structured, high quality, interpreted data by performing some specific tasks over raw data (e.g. labeling images, adding coordinates, tagging reports with categories, etc.). This role requires an active participation of users in the crowdsourcing effort and it may exploit special skills or require different levels of previous training.

\section{The Role of the Crowd in the Disaster Management Cycle}

The UN-SPIDER glossary defines the disaster management cycle as "the complete set of phases related to disasters and their management" [31]. While disaster relief agencies and organizations may conceptualize the disaster management phases differently, most models generally include the following ones: (i) mitigation; (ii) preparedness, (iii) response, and (iv) recovery.

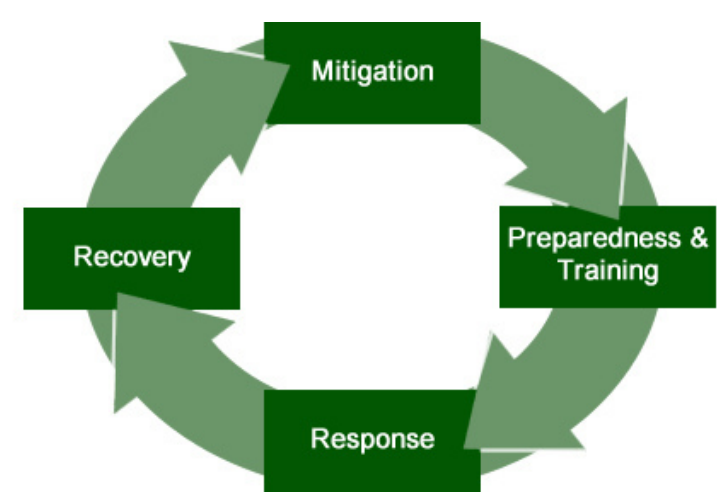


Fig. 2: The Disaster Management Cycle ${ }^{2}$

According to the standard definitions by the United Nations Office for Disaster Risk Reduction, mitigation refers to "the lessening or limitation of the adverse impacts of hazards and related disasters"; preparedness includes "the knowledge and capacities developed by governments, professional response and recovery organizations, communities and individuals to effectively anticipate, respond to, and recover from, the impacts of likely, imminent or current hazard events or conditions”; response involves "the provision of emergency services and public assistance during or immediately after a disaster in order to save lives, reduce health impacts, ensure public safety and meet the basic subsistence needs of the people affected"; recovery extends to "the restoration, and improvement where appropriate, of facilities, livelihoods and living conditions of disaster-affected communities, including efforts to reduce disaster risk factors" [32].

Even if, in practice, disasters tend to unfold in a continuum and the phases of the cycle may sometimes be difficult to isolate, the four crowdsourcing roles we have delimited can be applicable to the different phases of the cycle. This association can be valuable in order to identify specific persons whenever we are at a specific phase of the disaster. Thus, the role of the "crowd as a sensor" is especially relevant in the preparedness and training phases when sensors can provide critical information of events or sub-events for different geographical locations and at large scale [33, 34, 35, 36]. People may contribute data either inadvertently or by explicit consent: while GPS location services require users' explicit permission of access on both Android and iOS systems, other location sensors such as accelerometers and gyroscopes do not [37].

The role of the crowd as a "social computer" and as a "reporter" may be critical in the other three steps of the lifecycle (response, recovery, and mitigation) where people and organizations (citizens, volunteer groups, and emergency authorities) can engage in multi-way information sharing and provide near-real time updates on the events as they occur [38]. Given the ever-growing amount of information that people shares during a disaster, leveraging social media information posted on Twitter or Facebook becomes most relevant to facilitate situational awareness during an emergency [3]. Yet, there are a number of critical issues when using social media information: trustworthiness of the sources, veracity and accuracy of information, and privacy. Some of these issues are easier to handle as the crowd actively take the role of a "reporter". In that case, as people tend to be already identified, verifying the reported information and therefore both the trustworthiness of the source and the verification process are less problematic. The people who reports and uses the reported information can even be part of the crowdsourced verification process (e.g. within an Ushahidi deployment). Efficient methods to do it by applying simple recruiter reward and punishment approach have been proposed and tested [39,40].

The role of the crowd as a "microtasker" is especially relevant when it comes to produce and analyze structured data, both in the preparedness and training phases or

\footnotetext{
${ }^{2}$ By Dave Hallmon, CC BY-ND 2.0
} 
later in the response and recovery ones. Table 3 summarizes how the different types of crowdsourcing roles described above relate to the different phases of the emergency management cycle:

\begin{tabular}{|c|c|c|c|c|}
\hline & $\begin{array}{l}\text { Crowd as } \\
\text { a sensor }\end{array}$ & $\begin{array}{c}\text { Crowd as a } \\
\text { social com- } \\
\text { puter } \\
\end{array}$ & $\begin{array}{l}\text { Crowd as a } \\
\text { reporter }\end{array}$ & $\begin{array}{l}\text { Crowd as a } \\
\text { microtasker }\end{array}$ \\
\hline Preparedness & $\bullet$ & & & $\bullet$ \\
\hline Response & & $\bullet$ & $\bullet$ & $\bullet$ \\
\hline Recovery & & $\bullet$ & $\bullet$ & - \\
\hline Mitigation & $\bullet$ & $\bullet$ & $\bullet$ & \\
\hline
\end{tabular}

Table 1. Fig. 3: Crowdsourcing roles and disaster management cycles

\section{Crowdsourcing Tools and Disaster Management Phases}

In this section we present the different tools already available in the disaster management domain. We have classified them by establishing a set of dimensions related with the main characteristics of the tools. A preliminary list of tools was extracted from previous research on mobile technologies applied to governance [41]. Additional tools were then added through ongoing research on related sources and initiatives and turned out into the elaboration of a matrix. The four basic criteria for inclusion in the final list are:

1. The tool has been designed to be used on one or more phases of the emergency management cycle or, alternatively, it is applicable in this domain.

2. The tool leverages at least one of the crowdsourcing roles described in Section 3 (crowds as sensors, social computers, reporters, or micro-taskers) as part of the emergency management process,

3. The tool is currently available to end users,

4. The tool comes with enough information (i.e. demos, use cases, technical documentation, etc.) to make an accurate assessment of its functionalities.

Our review includes a total of 25 tools (16 disaster management platforms and 9 mobile apps) addressing different aspects of the disaster management cycle (DMC). The analysis does not include Mobile Data Collection Systems (MDCS) that are intended to collect specific information from targeted audiences via pre-designed surveys. In this regard, previous research on MDCS has shown that, from an initial list of 36 solutions, there are up to 24 tools currently available for use in humanitarian relief interventions [42]. ${ }^{3}$ While MDCS are relevant to our research, the platforms reviewed

${ }^{3}$ The NOMAD report includes a tool matrix of MDCS with different parameters: form features, synchronization, interoperability and connectivity, hardware requirements and capabilities supported, and system features and platform characteristics [42]. 
here have a broader scope and typically include additional functionalities (i.e. data aggregation, data filtering, data clustering, analytics, etc.). In fact, most MDCS could be integrated into DMC platforms as part of the data collection process treating each mobile data collector as a sensor or as we have defined previous considering the crowdsourcing type of "people as sensors" (i.e. FrontlineSMS and Ushahidi have already worked together to push incoming SMS to the Ushahidi and Crowdmap platforms). Similarly, our analysis does not consider the 250 emergency-related applications available in Google Play already reviewed in recent research [43].

\subsection{Taxonomy of Crowdsourcing Tools}

We have classified the different platforms and mobile apps upon the next four major characteristics: i) the phase of the management disaster cycle where it better applies to, ii) the availability of the tool and its source code, iii) the main core functionalities, and the iv) crowdsourcing role types:

- Management crisis lifecycle step: which one of the four phases of the disaster management cycle the tool applies to (mitigation, preparedness, response, and recovery).

- Availability of the tool: how the tool is made it available and under which license (open source license, commercial license).

- Core functionalities: which are the main functionalities that the tool is offering. We have identified the following subclasses:

- Information Retrieval (IR): the tool provides some functionalities to perform text analysis in order to obtain useful information from natural language sentences (structured or unstructured) or raw text (e.g. entity recognition).

- Data collection: the tool enables data collection from any device connected to the platform. It also provides data management functionalities on the data collected. This dimension is closely linked to the roles of the crowd as a sensor and as a social computer.

- Data filtering: the tool displays different filtering options over the data collected. The filtering can be done by keywords, by location, or by any other predefined filter.

- Data tagging: the tool provides tagging functionalities to facilitate the categorization of the collected data. This dimension is closely related with the crowdsourcing role of the crowd as a social computer.

- Mapping and navigation: the tool allows plotting geographic information related with the collected data in a map. It also may allow using this data for navigating in the map and retrieve data based on its geolocation. This dimension is closely related with the crowdsourcing role of the crowd as a sensor.

- Volunteer management tools: the tool comes with a dedicated module to manage the participation of digital or field volunteers (or both). 
- Crowdsourcing roles: the tool provides a framework for a particular crowdsourcing role, as in:

- Crowd as a sensor: the tool enables the collection of data from multiple devices, including mobile handsets, and each of these devices provides some local information which can be either automatically generated (run by sensors in the background) or human generated.

- Crowd as a social computer: the tool provides some applications or human computer interfaces enabling the users to collect data from social media and engage in social conversation if needed.

- Crowd as a reporter: the tools provides a platform where people can offer firsthand information on events as they are unfolding and allow the identification of a reporter versus an occasional user in order to preserve trustworthiness.

- Crowd as a microtasker: the tool provides applications or human computer interfaces for the execution of specific processing tasks by users. These tasks differ from the previous ones in that they that they exploit some specific knowledge and may also require a training phase to accomplish them.

\subsection{Main findings}

\subsubsection{Online platforms}

As regards online platforms, the majority of the solutions reviewed primarily support response and recovery-based efforts. Generally, the primary focus is on single, eventbased, location-specific, and dynamically-evolving scenarios that trigger an urgent response and the need for verified facts [44]. Nevertheless, most of the platforms could also be applicable in the mitigation and preparedness phases, especially those who have developed dedicated modules (i.e. Sahana contains different modules for organization registry, human resources, inventory, assets, etc. which focus on the mitigation and preparedness phases; OpenIR maps ecological risks revealed by infrared satellite data to identify vulnerable areas and support its emergency management). Crowdcrafting and ArcGIS enable developers and users to build custom applications or create and run projects that could also focus on mitigation and preparedness. Since social media information can also be leveraged at any stage of the emergency management cycle (i.e. at the preparedness and training phase, by constantly monitoring information to spot and follow emergency situations, or at the response phase, by communicating real-time between citizens or citizens and authorities) it is difficult to constrain potential uses of the platforms that include social media functionalities (i.e. Ushahidi and CrisisTracker) to just one phase.

Most of the platforms reviewed (10 out of 16) are either open source, have some open source components or can be used for free. As per core functionalities, the most common ones are data collection (12 instances) and data filtering and tagging (11 instances); up to 10 tools offer map and navigation functionalities and 6 of them include some module to manage volunteer effort. 


\subsubsection{Mobile apps}

The market for disaster management apps has remarkably expanded in the last few years $[45,46]$. Updates and alerts on hurricanes are now embedded in several apps that target residents in hurricane-prone areas [47]. However, even if these apps provide real-time information and updates georeferenced in storm maps, satellite images, and weather forecasts, the information flow remains one way, since it is delivered by the US National Hurricane Center or the US National Weather Service. In contrast, the apps listed in table 4 below tap into user-generated contents to supply updated information to both response organizations (i.e. UN or FEMA) and citizens.

As it is the case with online platforms, mobile applications reviewed here address the response phase of the disaster cycle (although four of them are also applicable in preparedness and one in recovery). Three of the platforms reviewed come with open source licenses and the remaining eight can be used for free.

As per core functionalities, the vast majority of the platforms allow data collection (8) and have mapping/navigation functionalities (9), while a few of them provide data filtering (4) and data tagging (4) functionalities. More specifically, Geopictures, UN Assign or FemaApp allow users to upload and share geo-tagged pictures, Pushpin and Vespucci are editing apps intended to facilitate edition and contribution of new data to OpenStreetMap. OSMTracker allows track logging and quick (voice) waypoint annotations when driving a car or on a bicycle, and OSMAnd is a map and navigation application with access to OpenStreetMap data that also offers both online and offline routing, with optical and voice guidance, for cars, bikes, and pedestrians. Jointly uses group messaging, social circles, and tasks lists to facilitate self-organization of local communities in disaster relief efforts. Fulcrum offers a suite of dedicated apps for disaster response (i.e. damage report, disaster shelter assessment, evacuee information, or post storm building damage report). Stormpins turns its users into local reporter by enabling them to share pin alerts with local TV, emergency managers and local communities. EmergencyAU, finally, also enables its users to upload pictures, videos, and comments about breaking emergencies.

\subsubsection{Ontologies}

Even though none of the platforms and mobile applications surveyed makes use of ontologies in their data collection, filtering, or tagging functionalities, it is worthwhile to highlight that there are a number of ontologies focusing on situational awareness and crisis management that could be applicable in this domain. A review of situational awareness ontologies is provided in [48], and proposals to formalize the basic components of situation awareness in an ontology can also be found in [49,50]. Further ontological approaches to disaster management can be found in $[51,52,53,54,55,56,57,58,59,60,61,62]$. Liu, Brewster and Shaw [63] offer a comprehensive review of 26 ontologies. The types of crisis information systems reviewed include critical infrastructures, resource management, decision support, response coordination, command and control, and other types such as humanitarian response and 
relief. While some of these ontologies have been completed and are publicly available, the others are the result of academic work and remain non-downloadable. The authors identified eleven subject-matters pointing at their interoperability -people, organizations, resources, disasters, geography, processes, infrastructure, damage, topography, hydrology and meteorology. 65\% of the existing ontologies are semantically interoperable. Only four of them (EM-DAT, UNEP-DTIE, Canadian Disaster Database, Australian Government Attorney-General's Department Disasters Database) are focused specifically on disaster management. But those are databaseoriented and do not provide a formal representation of disasters and their properties. Therefore, the review concludes that this is an emerging research field still with room for improvement. 


\begin{tabular}{|c|c|c|c|c|c|c|c|c|c|c|c|c|c|c|}
\hline Name & & & & Open source & & $\begin{array}{c}\text { Core } \\
\text { functionalities }\end{array}$ & & & & & & $\begin{array}{c}\text { Crowdsourcing } \\
\text { Types }\end{array}$ & & \\
\hline & Preparedness & Response & Recovery & $\begin{array}{l}\text { P=completely, } \\
\text { P=partially o-s wl } \\
\text { some components } \\
\text { licensed; } F=\text { Free } \\
\text { version available }\end{array}$ & $\begin{array}{l}\text { Information } \\
\text { Retrieval }\end{array}$ & Data collection & Data filtering & Data tagging & $\begin{array}{l}\text { Mapping and } \\
\text { Navigation }\end{array}$ & $\begin{array}{c}\text { Volunteer } \\
\text { Management tools }\end{array}$ & $\begin{array}{l}\text { Crowd as } \\
\text { sensors }\end{array}$ & $\begin{array}{l}\text { Crowd as social } \\
\text { computers }\end{array}$ & $\begin{array}{l}\text { Crowd as } \\
\text { reporters }\end{array}$ & $\begin{array}{c}\text { Crowd as } \\
\text { microtaskers }\end{array}$ \\
\hline $\begin{array}{l}\text { Ushahidi } \\
\text { Crowdmap }\end{array}$ & $\begin{array}{l}x \\
x\end{array}$ & $\begin{array}{l}x \\
x \\
\end{array}$ & $\begin{array}{l}x \\
x \\
\end{array}$ & $\begin{array}{r}Y \\
F\end{array}$ & & $\begin{array}{l}x \\
x\end{array}$ & $\begin{array}{l}x \\
x\end{array}$ & $\begin{array}{l}x \\
x\end{array}$ & $\begin{array}{l}x \\
x\end{array}$ & $\begin{array}{l}x \\
x\end{array}$ & $\begin{array}{l}x \\
x\end{array}$ & & & \\
\hline SwittRiver & & $x$ & $\hat{x}$ & Y & $\mathrm{x}$ & $\hat{x}$ & $\hat{x}$ & $\hat{x}$ & & $\hat{x}$ & $\hat{x}$ & $\mathrm{x}$ & & \\
\hline Eden (Sahana) & $x$ & $\frac{x}{x}$ & $x$ & $Y$ & & $x$ & $x$ & $x$ & $\mathrm{x}$ & & & $x$ & & \\
\hline Crowdcrafting & $\mathrm{x}$ & $\mathrm{x}$ & $\mathrm{x}$ & Y & & & & $x$ & & & & & $\mathrm{x}$ & $\mathrm{x}$ \\
\hline OpenlR & $x$ & & & $\mathrm{P}$ & & & & & $x$ & & & $x$ & & \\
\hline Recovers & $x$ & $x$ & $x$ & No & & $x$ & $\mathrm{x}$ & $x$ & $x$ & $\mathrm{x}$ & & $x$ & & \\
\hline ArcGIS & $x$ & $x$ & $\mathrm{x}$ & No & & & $\mathrm{x}$ & $\mathrm{x}$ & $\mathrm{x}$ & & & $\mathrm{x}$ & & \\
\hline PADDDtracker & & & & No & & $x$ & $x$ & $x$ & $x$ & & $x$ & & & \\
\hline Vizie & & $x$ & $x$ & No & & $x$ & $x$ & & & & $x$ & & & \\
\hline CrisisTracker & & $x$ & $x$ & Y & & $\mathrm{x}$ & $\mathrm{x}$ & $\mathrm{x}$ & & & & $x$ & $x$ & \\
\hline Souktel & $x$ & $\mathrm{x}$ & $\mathrm{x}$ & No & & $\mathrm{x}$ & $\mathrm{x}$ & & & & & $x$ & & \\
\hline Geochat & $x$ & $x$ & & $\mathrm{Y}$ & & $x$ & & & $\mathrm{x}$ & $\mathrm{x}$ & & $x$ & & \\
\hline InaSAFE & & . & & $Y$ & & $x$ & $\mathrm{x}$ & & $x$ & . & $x$ & . & & \\
\hline Geofeedia & & $\mathrm{x}$ & & No & $\mathrm{x}$ & $\hat{x}$ & $\hat{x}$ & & $\hat{x}$ & & $n$ & $\mathrm{x}$ & & \\
\hline Tomnod & & $x$ & $x$ & No & & & & $x$ & & $x$ & & & & $x$ \\
\hline \multicolumn{15}{|l|}{ Apps } \\
\hline Geopictures & & $\mathrm{x}$ & & $\mathrm{F}$ & & & & & & & & $x$ & & \\
\hline Fulcrum & $x$ & $x$ & & $F$ & & $x$ & & & & & $\mathrm{x}$ & & & \\
\hline Pushpin & $x$ & $x$ & & $\mathrm{~F}$ & & $x$ & & & $x$ & & $x$ & & & \\
\hline OSMtracker & & $\mathrm{x}$ & & $\mathrm{Y}$ & & & & & $\mathrm{x}$ & & $\mathrm{x}$ & & & \\
\hline OSMand & & $x$ & & $Y$ & & & & & $x$ & & $x$ & & & \\
\hline Vespucci & & $x$ & & Y & & $x$ & & & $x$ & & $x$ & & & \\
\hline UN-Asign & & $x$ & & $\mathrm{~F}$ & & $x$ & & & $\mathrm{x}$ & & $x$ & & & \\
\hline Jointly & & $\mathrm{x}$ & $x$ & $\mathrm{~F}$ & & $x$ & $\mathrm{x}$ & $x$ & $x$ & & & $x$ & & \\
\hline Stormpins & $x$ & $\mathrm{x}$ & & $\mathrm{F}$ & & $x$ & $\mathrm{x}$ & $x$ & $\mathrm{x}$ & & $\mathrm{x}$ & $\mathrm{x}$ & & \\
\hline EmergencyAUS & & $\mathrm{x}$ & & $\mathrm{F}$ & & $x$ & $x$ & $x$ & $\mathrm{x}$ & & & & $x$ & \\
\hline FEMA app & $x$ & $x$ & & $\mathrm{~F}$ & & $x$ & $x$ & $x$ & $x$ & & & & $x$ & \\
\hline
\end{tabular}

Fig. 4: Crowdsourcing roles and disaster management cycles 


\section{Conclusion}

Our motivation in developing a typology of crowdsourcing roles and reviewing stateof-the-art platforms and applications dealing with disaster and crisis control management was to stimulate new directions of research in the area of crowdsourced social media information applied to crisis events. While there is an emerging body of literature in this direction, comparative research on the current state of the art of tools and its functionalities is still scarce. In addition, we have found little connection between platform development and research in ontologies for disaster management, even if there are some synergies than could be explored further.

In this paper we have focused on the identification of a set of dimensions which we believe that characterize well the domain and we have classified a representative set of tools which are already available. Enriching platforms to structure their content as usable and reusable knowledge is related to contextual, ethical and legal problems that we put aside in this paper. We have shown that empowering online volunteers and organizations to offer a global response means including citizens as main players triggering such a response. Our pyramid clusters crowdsourcing roles based on users' involvement and level of data processing.

This faces new regulatory challenges in an emerging field. Privacy, data protection and security matter when we realize that accidents, earthquakes or bushfires hit people in states with a great diversity of legal and political systems. Principles, values and norms to be applied to platforms,and the processing of the information provided bottom-up by volunteers can be analyzed to the light of the relational perspective on law [64] and justice [63] aiming at fostering, empowering, and protecting citizens' participation and not only legal compliance. But liability in social media monitoring, tagging and filtering events cannot be ignored either [64]. Future research will further develop in greater detail the emergence of crowdsourcing typologies and types of regulation as they are currently being enabled by the new generation of mobile technology tools.

\section{$7 \quad$ Acknowledgements}

The research leading to this paper has been supported by two research grants from the Spanish Ministry of Economy and Competitiveness (MINECO) to the projects "CrowdCrissControl” (IPT-2012-0968-390000) and “Crowsourcing: instrumentos semánticos para el desarrollo de la participación y la mediación online (DER 201239492 -C02 -01)”. 


\section{$8 \quad$ References}

1. Meier, P. : Verily: Crowdsourced Verification for Disaster Response. iRevolution. http://irevolution.net/2013/02/19/verily-crowdsourcing-evidence/ (2013)

2. Fox, Z. : 2012. Red Cross Launches Social Media Disaster Response Center. Mashable, March 8, http://mashable.com/2012/03/07/red-cross-digital-operations-center/ (2012)

3. Cameron, M., Power, P., Robinson, B., Yin, J. Emergency Situation Awareness from Twitter for Crisis Management. In: Proceedings of SWDM'2012 Workshop held jointly with WWW' (2012)

4. Yin, J., Karimi, S., Robinson, B., Cameron, M. ESA: Emergency Situation Awareness via Microbloggers. In: CIKM'12, October 29-November 2, Maui, HI, USA (2012) http://www.ict.csiro.au/staff/jie.yin/files/de0418-yin-CIKM12.pdf

5. Sakaki, T., Okazaki, M. Matsuo, Y. : Tweet Analysis for Real-Time Event Detection and Earthquake Reporting System Development. IEEE Transactions on Knowledge and Data Engineering, 25, 4, pp. 919-931 (2013)

6. Caragea, C., McNeese, N., Jaiswal, A., Traylor, G., Kim, H., Mitra, P, Wu, D., Tapia, A., Giles, L., Jansen, B: Classifying text messages for the haiti earthquake. In: Proceedings of the $8^{\text {th }}$ International ISCRAM Conference, ISCRAM 11 (2011)

7. Li, J., Rao, H.: Twitter as a rapid response news service: An exploration in the context of the 2008 China earthquake. The Electronic Journal of Information Systems in Developing Countries, 42, 4, pp. 1-22 (2010)

8. Chowdhury, S.R., Imran, M., Asghar, M.R., Amer-Yahia, S., Castillo, C. : Tweet4act: Using incident-specific profiles for classifying crisis-related messages. In: The 10th International Conference on Information Systems for Crisis Response and Management, ISCRAM (2013) http://chato.cl/papers/roy_chowdhury_imran_rizwan_asghar_ameryahia_castillo_2013_tweet4act_classify_crisis_messages.pdf

9. Imran, M., Elbassuoni, S., Castillo, C., Diaz, F., Meier, P.: Extracting information nuggets from disaster-related messages in social media. In: The 10th International Conference on Information Systems for Crisis Response and Management (ISCRAM 2013) http://chato.cl/papers/imran_elbassuoni_castillo_diaz_meier_2013_extracting_information _nuggets_disasters.pdf

10. Robinson, B., Power, R., Cameron, M.: A sensitive twitter earthquake detector. In: Proceedings of the 22nd international conference on World Wide Web companion, WWW'13 Companion, pp. 999-1002 http://www2013.wwwconference.org/companion/p999.pdf (2013)

11. Power, R., Robinson, B., Ratcli, D.: Finding Fires with Twitter. In: Proceedings of the Australasian Language Technology Association Workshop, pp. 80-89 (2013) http://aclweb.org/anthology//U/U13/U13-1011.pdf.

12. Beneito-Montagut, R., Anson, S., Shaw, D., Brewster, C. : Resilience: Two case studies on governmental social media use for emergency communication. In: Proceedings of the Information Systems for Crisis Response and Management conference, ISCRAM 2013 1215 May), http://www.disaster20.eu/wordpress/wp-content/uploads/2013/06/BeneitoMontagut_ISCRAM13.pdf (2013)

13. Anderson, M.: Integrating social media into traditional management command and control structures: the square peg into the round hole. In: Emergency Media \& Public Affairs Conference, Melbourne 8 May http://hpe.com.au/empa/proceedings/Martin\%20Anderson.pdf (2012) 
14. Poblet, M.: Spread the word: the value of local information in disaster response. The Conversation, January 17, http://theconversation.com/spread-the-word-the-value-of-localinformation-in-disaster-response-11626 (2013)

15. Howe, J. 2006. The rise of crowdsourcing. Wired, June 14 (2006) http://www.wired.com/wired/archive/14.06/crowds.html

16. Howe, J.: Crowdsourcing: how the power of the crowd is driving the future of business. NY: Crown Publishing Group, NY (2009).

17. Doan, A., Ramakrishnan, R., and Halevy, A. Y.: Crowdsourcing systems on the WorldWide Web, Communications of the ACM, 54, 4, pp. 86-96 (2011)

18. Schenk, E., Guittard, C.: Towards a characterization of crowdsourcing practices. Journal of Innovation Economics 7/1, www.cairn.info/revue-journal-of-innovation-economics2011-1-page-93.htm (2011)

19. Geiger, D., Seedorf, S., Schulze, T., Nickerson, R. C., Schader, M.: Managing the Crowd: Towards a Taxonomy of Crowdsourcing Processes. In: AMCIS-Proceedings of the Seventeenth Americas Conference on Information Systems. Available at http://schader.bwl.unimannheim.de/fileadmin/files/schader/files/publikationen/Geiger_et_al._-_2011__Managing_the_Crowd_Towards_a_Taxonomy_of_Crowdsourcing_Processes.pdf.

20. Estellés-Arolas, E., González-Ladrón-de-Guevara, F.: Towards an integrated crowdsourcing definition. Journal of Information Science, 38, 2, pp. 189-200 (2012)

21. Zhao, Y., Zhu, Q.: Evaluation on crowdsourcing research: Current status and future direction. Information Systems Frontiers, pp. 1-18 (2012)

22. Haklay, M.: Citizen Science and Volunteered Geographic Information: Overview and Typology of Participation. In: D. Sui, S. Elwoold, M. Goodchild (Eds.) Crowdsourcing Geographic Science, , pp. 105-122, Springer, Netherlands (2013)

23. Saxton, G.D., Onook, O., Kishore, R.: Rules of Crowdsourcing: Models, Issues, and Systems of Control Information Systems Management, 30, 1, pp. 2-20 (2013)

24. Hetmank, L. Components and Functions of Crowdsourcing Systems: A Systematic Literature Review. In: Wirtschaftsinformatik Proceedings 2013. Paper 4. http://www.wi2013.de/proceedings/WI2013\%20-\%20Track\%201\%20-\%20Hetmank.pdf (2013)

25. Malone, T. W., Laubacher, R., Dellarocas, C. N.: Harnessing crowds: Mapping the genome of collective intelligence. MIT Sloan Research Paper 4732-09. http://18.7.29.232/handle/1721.1/66259 (2009)

26. Quinn, J. A., Bederson, B. B.: Human Computation: A survey and Taxonomy of a Growing Field”, CHI Conference, May 7-12, 2011 Vancouver, BC, Canada. http://alexquinn.org/papers/Human\%20Computation,\%20A\%20Survey\%20and\%20Taxon omy\%20of\%20a\%20Growing\%20Field\%20(CHI\%202011).pdf

27. Chamales, G.: Towards trustworthy social media and crowdsourcing. Wilson Center Commons Lab (2013),

http://www.wilsoncenter.org/sites/default/files/TowardsTrustworthySocialMedia_FINAL. pdf

28. Meier, P.: Why Bounded Crowdsourcing is Important for Crisis Mapping and Beyond. iRevolution. http://irevolution.net/2011/12/07/why-bounded-crowdsourcing/ (2011)

29. Prpic, J., Shukla, P.: The Theory of Crowd Capital. In: Proceedings of the Hawaii International Conference on Systems Sciences \#46. January 2013, Maui, Hawaii, USA. IEEE Computer Society Press. Available at http://ssrn.com/abstract=2193115 (2013)

30. Chatzimilioudis, G., Konstantinidis, A., Laoudias, C., Zeinalipour-Yazti, D.: Crowdsourcing with smartphones. Internet Computing, IEEE, 16, 5, pp. 36-44 (2012) 
31. UN-SPIDER: Glossary, Disaster Management. http://www.un-spider.org/glossary/disastermanagement-cycle (2014)

32. UNISDR: Terminology. http://www.unisdr.org/files/7817_UNISDRTerminologyEnglish.pdf (2009)

33. Sheik Dawood, M., Suganya, J., Karthika Devi, R. Athisha, G. A Review on Wireless Sensor Network Protocol for Disaster Management. International Journal of Computer Applications Technology and Research, 2, 2 pp. 141-146 (2013)

34. Radianti, J., Granmo, O.; Bouhmala, N., Sarshar, P.,Yazidi, A. , Gonzalez, J. Crowd Models for Emergency Evacuation: A Review Targeting Human-Centered Sensing. In: International Conference on System Sciences (HICSS), 46th Hawaii, pp. 156-165 (2013)

35. Kjaergaard, M.B., Wirz, M, Roggen, D., Troster, G.: Detecting pedestrian flocks by fusion of multi-modal sensors in mobile phones. In: Proceedings of the 2012 ACM Conference on Ubiquitous Computing, pp.240-249 (2012)

36. Boulos, M.N.K, Resch, B., Crowley, D.M., Breslin, J.G., Sohn, G., Burtner, R., Pike, W.A., Jezierski, E., Slayer Chuang, K-Y.: Crowdsourcing, citizen sensing and sensor web technologies for public and environmental health surveillance and crisis management: trends, OGC standards and application examples. International Journal of Health Geographics, 10, 67, pp 1-29, http://www.ij-healthgeographics.com/content/pdf/1476072X-10-67.pdf (2011)

37. Liu, M.: A Study of Mobile Sensing Using Smartphones. International Journal of Distributed Sensor Networks, pp. 1-11, Art. ID 272916 http://dx.doi.org/10.1155/2013/272916 (2013)

38. Chon, Y., Lane, N.D, Li, F., H. Cha, Zhao, F.: Automatically characterizing places with opportunistic crowdsensing using smartphones. In: Proceedings of the 2012 ACM Conference on Ubiquitous Computing, pp. 481-490 (2012)

39. Naroditskiy, V., Rahwan, I., Cebrian, M., Jennings, NR.: Verification in Referral-Based Crowdsourcing. PLoS ONE 7(10) e45924. doi:10.1371/journal.pone.0045924 (2012)

40. Tang, J., Cebrian, M., Giacobe, N.A., Kim, H.W., Kim, T., Wickert, D.B.: Reflecting on the DARPA Red Balloon Challenge. Communications of the ACM, 54, 4, pp. 78-85 (2011)

41. Poblet, M.: Rule of Law on the Go: New Developments of Mobile Governance. Journal of Universal Computer Science, 17, 3, pp. 498-512 (2011) http://www.jucs.org/jucs_17_3/rule_of_law_on_the/jucs_17_03_0498_0512_poblet.pdf

42. Jung, C.: Data collection mobile systems: A review of the current state of the field. (2011) http://www.parkdatabase.org/files/documents/nomad_mdc_research.pdf

43. Gómez, D., Bernardos, A.M, Portillo, J.I., Tarrío, P., Casar, J.R.: A Review on Mobile Applications for Citizen Emergency Management. In: Highlights on Practical Applications of Agents and Multi-Agent Systems, Communications in Computer and Information Science, 365, pp. 190-201 (2013)

44. Coppola, D.P. Introduction to international disaster management. Elsevier, Burlington, MA (2011)

45. Poblet, M. (ed.): Mobile Technologies for Conflict Management: Online Dispute Resolution, Governance, Participation. Springer-Verlag, Berlin, Dordrecht (2011)

46. Shih, F., Seneviratne, O., Liccardi, I., Patton, E., Meier, P., \& Castillo, C.: Democratizing mobile app development for disaster management. In: AIPP13, Joint Proceedings of the Workshop on AI Problems and Approaches for Intelligent Environments and Workshop on Semantic Cities, pp. 39-42 (2013) 
47. Peckham, M.: 6 Apps for Tracking Hurricane Isaac with Your Tablet or Smartphone, http://techland.time.com/2012/08/27/6-apps-for-tracking-hurricane-isaac-with-your-tabletor-smartphone/\#ixzz2bFbr0Nuo (2012)

48. Baumgartner, N., Retschitzegger, W.: A Survey of Upper Ontologies for Situation Awareness. In: Proceedings of the $4^{\text {th }}$ International Conference on Knowledge Sharing and Collaborative Engineering (KSCE 2006) http://pdf.aminer.org/000/260/167/a_very_high_level_language_to_capture_knowledge_fo r_an.pdf (2006)

49. Kokar, M.M., Matheus, C.J., Baclawski, K.. Ontology-based situation awareness. Information Fusion, 10, 1, PP. 83-89 (2009)

50. Baumgartner, N., Gottesheimb, W., Mitschb, S., Retschitzeggerc, W., Schwinger, W.: BeAware!-Situation awareness, the ontology-driven way. Data \& Knowledge Engineering, 69, 11, pp. 1181-1193 (2010)

51. Klien, E., Lutz, M., \& Kuhn, W.: Ontology-based discovery of geographic information services: An application in disaster management. Computers, Environment and Urban Systems, 30, 1, pp. 102-123 (2006)

52. Xu, W., Zlatanova, S.: Ontologies for Disaster Management Response. In: J. Li, S. Zlatanova, A.G. Fabbri (eds.). Geomatics Solutions for Disaster Management. Lecture Notes in Geoinformation and Cartography, Doi: 10.1007/978-3-540-72108-6_13, Springer, Berlin, Heidelberg, pp. 185-200 (2007)

53. Ratnam, K. R., Karunaratne, D. D.: Application of Ontologies in Disaster Management. http://icter.org/conference/sites/default/files/icter/IITC-2008p24.pdf (2008)

54. Babitski, G., Bergweiler, S., Hoffmann, J., Schön, D., Stasch, C., \& Walkowski, A. C.: Ontology-based integration of sensor web services in disaster management. In: K. Janowicz, M. Raubal, S. Levashk (eds.), GeoSpatial Semantics. Springer, Berlin, pp. 103121 (2009)

55. Murgante, B., Scardaccione G., Las Casas, G.: Building ontologies for disaster management: seismic risk domain. In: in Krek A., Rumor M., Zlatanova S., Fendel E. M. (Eds), Urban and Regional Data Management pp. 259-269, CRC Press, Taylor \& Francis, London (2009)

56. Babitski, G., Bergweiler, S., Grebner, O., Oberle, D., Paulheim, H., Probst, F.: SoKNOS Using Semantic Technologies in Disaster Management Software. In: G. Antoniou, M. Grobelnik, E. Simperl, B. Parsia, D. Plexousakis, P. De Leenheer, J. Pan, The Semantic Web: Research and Applications, LNCS 6644, pp. 183-197 (2011)

57. Kalabokidis, K., Athanasis, N., Vaitis, M.: OntoFire: an ontology-based geo-portal for wildfires. Natural Hazards Earth System Science, 11, pp. 3157-3170 (2011)

58. K. Grolinger, K.P. Brown, M.A.M. Capretz: From Glossaries to Ontologies: Disaster Management Domain. In: The 23rd International Conference on Software Engineering and Knowledge Engineering, Miami Beach, Florida, USA, pp. 402-407 (2011) 2011.http://www.ksi.edu/seke/Proceedings/seke11/127_Katarina_Grolinger.pdf

59. Ortmann, J., Limbu, M., Wang, D., \& Kauppinen, T.: 2011. Crowdsourcing linked open data for disaster management. In: Proceedings of the Terra Cognita Workshop on Foundations, Technologies and Applications of the Geospatial Web in conjunction with the ISWC, $\quad$ pp. 11-22, http://iswc2011.semanticweb.org/fileadmin/iswc/Papers/Workshops/Terra/paper2.pdf

60. Apisakmontri, P., Nantajeewarawat, E., Buranarach, M., \& Ikeda, M.: Towards the Use of Upper Ontologies for Refugee Emergencies in Disaster Management. ACIS 2013 http://saki.siit.tu.ac.th/acis2013/uploads_final/53_6e51b17e7cc62702a63014647081b860/ ACIS_pasinee_v3.pdf 
61. Mansourizadeh, M., Mharooni, M.: A review of semantic mapping techniques of natural disaster ontologies. In: 5th Conference on Information and Knowledge Technology (IKT 2013), pp. 332-337 (2013)

62. Li, L., Li, T.: An empirical study of ontology-based multi-document summarization in disaster management. IEEE Transactions on Systems, Man, and Cybernetics Systems, 44, 2, pp. 162-171 (2014)

63. Liu, S., Brewster, C., Shaw, D.: Ontologies for Crisis Management: A Review of State of the Art in Ontology Design and Usability. In: T. Comes, F. Fiedrich, S. Fortier, J. Geldermann and L. Yang (eds.), Proceedings of the 10th International ISCRAM Conference - Baden-Baden, Germany, May 2013.http://www.disaster20.eu/wordpress/wpcontent/uploads/2013/06/Liu_ISCRAM13.pdf (2013)

64. Casanovas, P., Poblet, M.: Concepts and Fields of Relational Justice.In: Sartor, G., Casanovas, P., Casellas, N., Rubino, R. (Eds) Computable Models of the Law: Languages, Dialogue, Games, Ontologies. LNAI 4884, Springer Verlag, Berlin, Heidelberg, pp. 323339 (2008)

65. Casanovas,P., Poblet, M.: The Future of Law: Relational Law and next Generation of Web Services. In: M. Fernández-Barrera et al. (Eds), The Future of Law and Technology: Looking into the Future. Selected Essays, pp. 137-156, European Press Academic Publishing, Florence (2009)

66. Poblet, M.; Leshinsky, R., Zeleznikow, J.: Digital neighbours : Even Good Samaritan crisis mappers need strategies for legal liability, Planning News, 38, 11, Dec 2012: 20-21. <http://search.informit.com.au/documentSummary;dn=002163980680827;res=IELBUS > 